\title{
Number of Full Term Births
}

National Cancer Institute

\section{Source}

National Cancer Institute. Number of Full Term Births. NCI Thesaurus. Code C122190.

A measurement of the total number of birth events at which the gestational age of the neonate is 39 weeks and 0 days through 40 weeks and 6 days. 